\title{
Action of melatonin on squamous cell carcinoma and other tumors of the oral cavity (Review)
}

\author{
ANTONIO CUTANDO ${ }^{1}$, ANTONIO LÓPEZ-VALVERDE ${ }^{2}$, JOAQUIN DE VICENTE ${ }^{2}$, \\ JULIAN LÓPEZ GIMENEZ ${ }^{1}$, ISAAC ALIAS CARCÍA ${ }^{1}$ and RAFAEL GOMEZ DE DIEGO ${ }^{3}$ \\ ${ }^{1}$ Department of Special Care in Dentistry, School of Dentistry, University of Granada, Granada 18071; \\ ${ }^{2}$ Department of Surgery, School of Dentistry, Faculty of Medicine, University of Salamanca, Salamanca 37007; \\ ${ }^{3}$ Department of Surgery, School of Dentistry, University Alfonso X, Madrid 28691, Spain
}

Received June 5, 2013; Accepted December 3, 2013

DOI: $10.3892 / \mathrm{ol} .2014 .1813$

\begin{abstract}
Melatonin (MLT; $N$-acetyl-5-metoxy-tryptamine) is a hormone that is principally synthesized in the pineal gland. MLT has been shown to exhibit a variety of functions. The hormone, which is a free radical scavenger, plays an immunomodulatory role, stimulates the proliferation and synthesis of type I collagen and promotes bone formation. Moreover, MLT exerts oncostatic activity through several biological mechanisms, including antiproliferative functions, stimulation of anticancer immunity, modulation of oncogene expression and anti-inflammatory, antioxidant and antiangiogenic effects. In addition, MLT inhibits human cancer cell growth in culture, and previous clinical studies have also confirmed its anticancer properties in vivo. With regard to the underlying mechanisms of MLT in tumor processes, including oral cavity tumors such as epidermoid carcinoma, knowledge of the role played by the MT1 and 2 membrane receptors, MT3 and the calmodulin cytosolic binding sites, as well as the nuclear receptors of the RZR/ROR family, is increasing. It has been hypothesized that exogenous restoration of MT1 (MTNR1A) expression inhibits the growth of oral squamous cell carcinoma cells lacking the expression of the receptor. The tumor suppressing functions of MLT and the presence of the MT1 receptor in various tumors indicate that the receptor may play a pivotal role in oral carcinogenesis. The current review discusses the clinical significance of MLT in oral cancer.
\end{abstract}

\section{Contents}

1. Introduction

2. Oncostatic properties of melatonin (MLT)

3. Expression and function of MT1 and MT2 receptors

4. Conclusion

Correspondence to: Dr Antonio Cutando, Department of Special Care in Dentistry, School of Dentistry, University of Granada, Granada 18071, Spain

E-mail: acutando@ugr.es

Key words: melatonin, carcinoma, tumors

\section{Introduction}

Melatonin (MLT) or $N$-acetyl-5-metoxy-tryptamine, is a hormone synthesized in various organs of the body, but principally in the pineal gland (1). The pineal gland produces MLT in a circadian manner, synchronizing a number of biological processes in a 24-h, day-night rhythm. An internal 24-h time keeping system (biological clock) regulated by MLT controls the sleep-wake cycle (2). MLT affects numerous aspects of circadian and circannual rhythms, including sleep, actions that are mediated by the binding of indoleamine to membrane receptors $(3,4)$. A number of studies have shown the various actions of MLT with regard to aspects of intracellular functions associated with mechanisms that are independent of the action of the hormone on the cellular membrane receptors. For these actions, nuclear receptors for MLT have been identified in the cells of the central nervous system and peripheral organs (5-7). Since MLT has lipophilic properties, the hormone is able to reach intracellular organelles, including the nucleus and mitochondria (8). In the cell interior, MLT is capable of binding to specific cytosolic proteins, including protein kinase $C(9,10)$, calmodulin $(10,11)$, calreticulin (12) and quinone reductase-2 (QR2) (13).

Currently, MLT is not regarded as a hormone in the classical sense, but functions as a cell protector since it is not synthesized in a single organ and does not exert effects upon a specific target organ. Studies have shown that MLT is a molecule with paracrine, autocrine and antioxidant effects that exerts diverse receptor-dependent and -independent actions $(14,15)$. Overall, MLT exhibits homeostatic functions and pleiotropic effects relevant to cell protection and survival mechanisms (16).

MLT is produced in several organs, and MLT-forming enzymes are found in a number of tissues, including the retina $(17,18)$, ovaries $(19,20)$, gastrointestinal tract $(21,22)$ and cells of the immune system (23). MLT is released into the blood and then passively diffuses into the oral cavity via saliva and the oral mucosa (24). MLT in the saliva is found in concentrations up to $70 \%$ lower than those in blood, and considering that MLT is bound to plasma proteins, salivary MLT represents the percentage of free MLT that is not albumin-bound (25). The measurement of salivary MLT 
is a useful non-invasive technique for monitoring MLT circadian rhythmicity (26). The major metabolite of MLT is 6-hydroxymelatonin sulfate (derived from 6-hydroxylation and conjugation primarily to sulfates in the liver), which is excreted in the urine in a larger amount at night than during the day (1). MLT is also converted to cyclic 3-hydroxymelatonin, presumably in all cells, and this metabolite is excreted in urine (27).

\section{Oncostatic properties of MLT}

It has been shown that MLT exhibits oncostatic properties on a wide variety of tumors, including prostate, colorectal, neural, ovarian, breast and cervical cancers, and sarcomas, hepatocarcinomas, melanomas, larynx carcinomas and skin carcinomas (28). The oncostatic effects of MLT have been well studied in hormone-dependent tumors. Extensive evidence on the oncostatic activity of MLT is based on in vitro studies carried out in cell lines derived from human tumors and murine tumoral models. The general conclusions of these studies are that MLT inhibits cell proliferation and induces apoptosis in the majority of tumor cell lines. Mechanisms of cancer inhibition by MLT include antioxidant effects, the regulation of estrogen receptor expression and transactivation, modulation of the enzymes involved in the local synthesis of estrogens, modulation of the cell cycle, differentiation and apoptosis, inhibition of telomerase activity, antiangiogenesis, prevention of circadian disruption, activation of the immune system and epigenetic factors. There are numerous studies that have investigated the mechanisms of MLT on various tumor types, as well as reviews summarizing the results of studies on a number of malignant neoplasms (28-33).

MLT has the capability of scavenging radicals and radical-associated reactants, stimulating the expression of antioxidative enzymes and reducing the expression of pro-oxidants $(34,35)$. The anticarcinogenic actions of MLT associate in part with the antioxidative and free radical scavenging activities. The anti-estrogenic properties of MLT depend on the ability to decrease the expression of estrogen receptor- $\alpha(E R \alpha)$, and to inhibit the binding of the $E_{2}-E R$ complex to the estrogen response element on DNA $(28,36)$. These effects are exerted through MLT binding to the specific membrane receptor, MT1. By contrast, the inactivation of calmodulin by MLT is an additional method in which this hormone may interact with the estrogen signaling pathway (37). MLT shares properties with the selective ER and enzyme modulators which explains the oncostatic properties of MLT on estrogen-dependent tumors (28). Other mechanisms of action, including the pro-apoptotic effects of MLT on tumor cells (38) and the inhibition of telomerase activity (39), are only partially understood.

MLT exerts direct antiangiogenic effects through inhibiting vascular endothelial growth factor. Indirect effects are also exhibited by MLT through inhibiting other tumor growth factors, including epidermal growth factor, endothelin-1 and insulin-like growth factor 1 , which are significant mitogens that stimulate cancer angiogenesis (40). In addition, MLT neutralizes reactive oxygen species. Studies on the antiangiogenic properties of MLT are of significant importance for possible future clinical applications (28). MLT is also synthesized by lymphoid organs, including bone marrow, the thymus and lymphocytes, and is considered an immunoenhancer agent. The administration of MLT stimulates the production of natural killer cells, monocytes, leukocytes, interleukin (IL)-2, -6 and -12 , interferon- $\gamma$ and TNF- $\alpha$ through binding to specific membrane and nuclear receptors present in these cells (41). Finally, novel roles for MLT in the epigenetic modulation of gene transcription have also been indicated (28).

\section{Expression and function of MT1 and MT2 receptors}

MLT and its metabolites interact with the intracellular protein, calmodulin, RZR/ROR family nuclear-membrane receptors and MT1 and 2 receptors located in the cell membrane (42). The MT1 and 2 receptors were initially referred to as Mella and Mel1b, but were later classified as MT1 and MT2 receptors by the International Union of Basic and Clinical Pharmacology (43). The MT1 and 2 receptors are members of the G-protein-coupled receptor (GPCR) family and share a number of their amino acid sequences (44). With the use of recombinant MLT receptors, the MT1 receptor has been shown to be coupled to various $\mathrm{G}$ proteins that are able to mediate adenylyl cyclase inhibition and phospholipase $C \beta$ activation. The MT2 receptor is also coupled to the inhibition of adenylyl cyclase and additionally inhibits the soluble guanylyl cyclase pathway (45).

A third member of the MLT receptor family is the X-linked orphan, GPR50 (46), which shares $45 \%$ homology with the MT1 and 2 receptors. However, the ligand of GPR50 and its physiological function remain unclear, although an involvement in key hypothalamic functions, including the regulation of the hypothalamopituitary axes, has been indicated (47). Moreover, orphan GPCRs heterodimerize with GPCRs that have identified ligands, resulting in the regulation of the latter GPCR function (48). Deletion of the large C-terminal tail of GPR50 suppresses the inhibitory effect of GPR50 on MT1 without affecting heterodimerization, indicating that this domain regulates the interaction of regulatory proteins to MT1 (49).

Investigation has also been conducted into an MT3 receptor/binding site. Despite MT3 being a presumptive membrane receptor, following stimulation, the transduction cascade and biological consequences have not been elucidated. Moreover, a number of studies support the hypothesis that the MT3 binding site is an enzyme, QR2, rather than a membrane MLT receptor (50). It has been hypothesized that MLT is a co-substrate of QR2, which itself is believed to be a an antioxidant and detoxifying enzyme that changes behavior depending on the co-substrates available. MLT is a naturally occurring substance whose levels consequently fluctuate with the light/dark cycle, the health/disease state and aging. Therefore, these alterations in MLT production, under physiological or pathological conditions, are likely to affect the activity of QR2. However, the hypothesis that MTL is a substrate or co-substrate of this enzyme is controversial (51).

With regard to the mechanisms behind MLT anticancer function in the oral cavity, the present data remain insufficient. Epidermoid carcinoma is one of the most frequent tumors of the oral cavity, with aggressive behavior. In patients with epidermoid 
carcinoma in whom the presence of the MT1 receptor has been studied through mRNA expression, MT1 has been shown to be diminished or non-existent. This is in contrast to what occurs in the normal epithelium of the oral cavity. It has been shown that in human cancers, including oral squamous cell carcinoma, DNA methylation of 5'-CpG islands (cytosine and guanine separated by phosphate) is a major cause of tumor-suppressor gene inactivity (52). In these tumors, there is an inverse correlation between MT1 receptor expression and DNA methylation. By contrast, the absence of immunoreactive MT1 is associated significantly with a greater tumor size and poorer survival prognosis. In a previous study, restoration of the exogenous MT1 receptor was found to inhibit the growth of epidermoid cells lacking the expression of this receptor (53). In this respect, it has been hypothesized that MTNR1A is a likely target for epigenetic silencing at the homozygously deleted region at $4 \mathrm{q} 35$, detected in these tumors (53). In precancerous oral diseases, including leukoplakia and lichen planus, reactive oxygen species are also involved in pathogenesis $(54,55)$. MLT may protect against these pathologies due to its antioxidant properties. However, further studies are required to assess the efficacy of MLT treatment for these cases (56). MLT may be useful to treat diseases of the oral cavity in patients with low concentrations of the hormone, but not where the tissues express MT1 and 2 receptors (57).

\section{Conclusion}

In summary, the role of MLT in carcinogenic processes is being increasingly studied. However, information concerning the involvement of MLT in tumors of the oral cavity is preliminary. The role of MLT, the MT1, 2 and 3 receptors and the RZR nuclear receptors requires further investigation.

\section{References}

1. Reiter RJ: Pineal melatonin: cell biology of its synthesis and of its physiological interactions. Endocr Rev 12: 151-180, 1991.

2. Reiter RJ, Tan DX and Fuentes-Broto L: Melatonin: a multitasking molecule. Prog Brain Res 181: 127-151, 2010.

3. Vanëcek J: Melatonin binding sites. J Neurochem 51: 1436-1440, 1988.

4. Cajochen C, Kräuchi K and Wirz-Justice A: Role of melatonin in the regulation of human circadian rhythms and sleep. J Neuroendocrinol 15: 432-437, 2003.

5. Acuña-Castroviejo D, Reiter RJ, Menéndez-Peláez A, Pablos MI and Burgos A: Characterization of high-affinity melatonin binding sites in purified cell nuclei of rat liver. J Pineal Res 16: $100-112,1994$.

6. Jetten AM, Kurebayashi S and Ueda E: The ROR nuclear orphan receptor subfamily: critical regulators of multiple biological processes. Prog Nucleic Acid Res Mol Biol 69: 205-247, 2001.

7. Carlberg C, Hooft van Huijsduijnen R, Staple JK, DeLamarter JF and Becker-André M: RZRs, a new family of retinoid-related orphan receptors that function as both monomers and homodimers. Mol Endocrinol 8: 757-770, 1994.

8. Reiter RJ, Paredes SD, Manchester LC and Tan DX: Reducing oxidative/nitrosative stress: a newly-discovered genre for melatonin. Crit Rev Biochem Mol Biol 44: 175-200, 2009.

9. Antón-Tay F, Ramírez G, Martínez I and Benítez-King G: In vitro stimulation of protein kinase $\mathrm{C}$ by melatonin. Neurochem Res 23: 601-606, 1998.

10. Soto-Vega E, Meza I, Ramírez-Rodríguez G and Benitez-King G: Melatonin stimulates calmodulin phosphorylation by protein kinase C. J Pineal Res 37: 98-106, 2004.

11. Turjanski AG, Estrin DA, Rosenstein RE, McCormick JE, Martin SR, Pastore A, Biekofsky RR and Martorana V: NMR and molecular dynamics studies of the interaction of melatonin with calmodulin. Protein Sci 13: 2925-2938, 2004
12. Macías M, Escames G, Leon J, Coto A, Sbihi Y, Osuna A and Acuña-Castroviejo D: Calreticulin-melatonin. An unexpected relationship. Eur J Biochem 270: 832-840, 2003.

13. Nosjean O, Ferro M, Coge F, Beauverger P, Henlin JM, Lefoulon F, Fauchere JL, Delagrange P, Canet E and Boutin JA: Identification of the melatonin-binding site MT3 as the quinone reductase 2. J Biol Chem 275: 31311-31317, 2000.

14. Tan DX, Manchester LC, Hardeland R, Lopez-Burillo S, Mayo JC, Sainz RM and Reiter RJ: Melatonin: a hormone, a tissue factor, an autocoid, a paracoid, and an antioxidant vitamin. J Pineal Res 34: 75-78, 2003.

15. Hardeland R, Tan DX and Reiter RJ: Kynuramines, metabolites of melatonin and other indoles: the resurrection of an almost forgotten class of biogenic amines. J Pineal Res 47: 109-126, 2009.

16. Luchetti F, Canonico B, Betti M, Arcangeletti M, Pilolli F, Piroddi M, Canesi L, Papa S and Galli F: Melatonin signaling and cell protection function. FASEB J 24: 3603-3624, 2010.

17. Wiechmann AF and Summers JA: Circadian rhythms in the eye: the physiological significance of melatonin receptors in ocular tissues. Prog Retin Eye Res 27: 137-160, 2008.

18. Scher J, Wankiewicz E, Brown GM and Fujieda H: MT(1) melatonin receptor in the human retina: expression and localization. Invest Ophthalmol Vis Sci 43: 889-897, 2002.

19. Itoh MT, Ishizuka B, Kuribayashi Y, Amemiya A and Sumi Y: Melatonin, its precursors, and synthesizing enzyme activities in the human ovary. Mol Hum Reprod 5: 402-408, 1999.

20. Tamura H, Nakamura Y, Korkmaz A, Manchester LC, Tan DX, Sugino N and Reiter RJ: Melatonin and the ovary: physiological and pathophysiological implications. Fertil Steril 92: 328-343, 2009.

21. Bubenik GA: Localization, physiological significance and possible clinical implication of gastrointestinal melatonin. Biol Signals Recept 10: 350-366, 2001.

22. Konturek SJ, Konturek PC, Brzozowska I, Pawlik M, Sliwowski Z, Cześnikiewicz-Guzik M, Kwiecień S, Brzozowski T, Bubenik GA and Pawlik WW: Localization and biological activities of melatonin in intact and diseased gastrointestinal tract (GIT). J Physiol Pharmacol 58: 381-405, 2007.

23. Carrillo-Vico A, Calvo JR, Abreu P, Lardone PJ, García-Muriño S, Reiter RJ and Guerrero JM: Evidence of melatonin synthesis by human lymphocytes and its physiological significance: possible role as intracrine, autocrine, and/or paracrine substance. FASEB J 18: 537-539, 2004.

24. Laakso ML, Porkka-Heiskanen T, Alila A, Stenberg D and Johansson G: Correlation between salivary and serum melatonin: dependence on serum melatonin levels. J Pineal Res 9: 39-50, 1990.

25. Kennaway DJ and Voultsios A: Circadian rhythm of free melatonin in human plasma. J Clin Endocrinol Metab 83: 1013-1015, 1998

26. Nowak R, McMillen IC, Redman J and Short RV: The correlation between serum and salivary melatonin concentrations and urinary 6-hydroxymelatonin sulphate excretion rates: two non-invasive techniques for monitoring human circadian rhythmicity. Clin Endocrinol (Oxf) 27: 445-452, 1987.

27. Tan DX, Manchester LC, Reiter RJ, Plummer BF, Hardies LJ, Weintraub ST, Vijayalaxmi and Shepherd AM: A novel melatonin metabolite, cyclic 3-hydroxymelatonin: a biomarker of in vivo hydroxyl radical generation. Biochem Biophys Res Commun 253: 614-620, 1998

28. Mediavilla MD, Sanchez-Barcelo EJ, Tan DX, Manchester L and Reiter RJ: Basic mechanisms involved in the anti-cancer effects of melatonin. Curr Med Chem 17: 4462-4481, 2010.

29. Ravindra T, Lakshmi NK and Ahuja YR: Melatonin in pathogenesis and therapy of cancer. Indian J Med Sci 60: 523-535, 2006.

30. Jung-Hynes B, Reiter RJ and Ahmad N: Sirtuins, melatonin and circadian rhythms: building a bridge between aging and cancer. J Pineal Res 48: 9-19, 2010.

31. Benítez-King G, Soto-Vega E and Ramírez-Rodriguez G: Melatonin modulates microfilament phenotypes in epithelial cells: implications for adhesion and inhibition of cancer cell migration. Histol Histopathol 24: 789-799, 2009.

32. Cos S, González A, Martínez-Campa C, Mediavilla MD, Alonso-González C and Sánchez-Barceló EJ: Estrogen-signaling pathway: a link between breast cancer and melatonin oncostatic actions. Cancer Detect Prev 30: 118-128, 2006.

33. Cos S, González A, Martínez-Campa C, Mediavilla MD, Alonso-González C and Sánchez-Barceló EJ: Melatonin as a selective estrogen enzyme modulator. Curr Cancer Drug Targets 8: 691-702, 2008. 
34. Rodriguez C, Mayo JC, Sainz RM, Antolín I, Herrera F, Martín V and Reiter RJ: Regulation of antioxidant enzymes: a significant role for melatonin. J Pineal Res 36: 1-9, 2004.

35. Reiter RJ, Tan DX, Osuna C and Gitto E: Actions of melatonin in the reduction of oxidative stress. A review. J Biomed Sci 7: 444-458, 2000.

36. Molis TM, Spriggs LL and Hill SM: Modulation of estrogen receptor mRNA expression by melatonin in MCF-7 human breast cancer cells. Mol Endocrinol 8: 1681-1690, 1994.

37. Rato AG, Pedrero JG, Martinez MA, del Rio B, Lazo PS and Ramos S: Melatonin blocks the activation of estrogen receptor for DNA binding. FASEB J 13: 857-868, 1999.

38. Sainz RM, Mayo JC, Rodriguez C, Tan DX, Lopez-Burillo S and Reiter RJ: Melatonin and cell death: differential actions on apoptosis in normal and cancer cells. Cell Mol Life Sci 60: 1407-1426, 2003.

39. Leon-Blanco MM, Guerrero JM, Reiter RJ, Calvo JR and Pozo D: Melatonin inhibits telomerase activity in the MCF-7 tumor cell line both in vivo and in vitro. J Pineal Res 35: 204-211, 2003.

40. Park SY, Jang WJ, Yi EY, Jang JY, Jung Y, Jeong JW and Kim YJ: Melatonin suppresses tumor angiogenesis by inhibiting HIF-1alpha stabilization under hypoxia. J Pineal Res 48: 178-184, 2010.

41. Szczepanik M: Melatonin and its influence on immune system. J Physiol Pharmacol 58 (Suppl 6): 115-124, 2007.

42. Dubocovich ML and Markowska M: Functional MT1 and MT2 melatonin receptors in mammals. Endocrine 27: 101-110, 2005.

43. Dubocovich ML, Cardinali DP, Guardiola-Lemaitre B Hagan RM, Sugden D, Vanhoutte PM and Yocca FD (eds): The IUPHAR compendium of receptor characterization and classification. In: Melatonin Receptors. IUPHAR Media, London, pp187-193, 1998.

44. Reppert SM: Melatonin receptors: molecular biology of a new family of $\mathrm{G}$ protein-coupled receptors. J Biol Rhythms 12 : 528-531, 1997.

45. von Gall C, Stehle JH and Weaver DR: Mammalian melatonin receptors: molecular biology and signal transduction. Cell Tissue Res 309: 151-162, 2002.

46. Ivanova EA, Bechtold DA, Dupré SM, Brennand J, Barrett P, Luckman SM and Loudon AS: Altered metabolism in the melatonin-related receptor (GPR50) knockout mouse. Am J Physiol Endocrinol Metab 294: E176-E182, 2008.

47. Sidibe A, Mullier A, Chen P, Baroncini M, Boutin JA, Delagrange P, Prevot V and Jockers R: Expression of the orphan GPR50 protein in rodent and human dorsomedial hypothalamus, tanycytes and median eminence. J Pineal Res 48: 263-269, 2010.
48. Civelli O, Saito Y, Wang Z, Nothacker HP and Reinscheid RK: Orphan GPCRs and their ligands. Pharmacol Ther 110: 525-532, 2006.

49. Levoye A, Dam J, Ayoub MA, Guillaume JL, Couturier C, Delagrange P and Jockers R: The orphan GPR50 receptor specifically inhibits MT1 melatonin receptor function through heterodimerization. EMBO J 25: 3012-3023, 2006.

50. Tan DX, Manchester LC, Terron MP, Flores LJ, Tamura H and Reiter RJ: Melatonin as a naturally occurring co-substrate of quinone reductase-2, the putative MT3 melatonin membrane receptor: hypothesis and significance. J Pineal Res 43: 317-320, 2007.

51. Boutin JA, Marcheteau E, Hennig P, Moulharat N, Berger S, Delagrange P, Bouchet JP and Ferry G: MT3/QR2 melatonin binding site does not use melatonin as a substrate or a co-substrate. J Pineal Res 45: 524-531, 2008.

52. Ha PK and Califano JA: Promoter methylation and inactivation of tumour-suppressor genes in oral squamous-cell carcinoma. Lancet Oncol 7: 77-82, 2006.

53. Nakamura E, Kozaki K, Tsuda H, Suzuki E, Pimkhaokham A, Yamamoto G, Irie T, Tachikawa T, Amagasa T, Inazawa J and Imoto I: Frequent silencing of a putative tumor suppressor gene melatonin receptor $1 \mathrm{~A}$ (MTNR1A) in oral squamous-cell carcinoma. Cancer Sci 99: 1390-1400, 2008.

54. Gómez-Moreno G, Guardia J, Ferrera MJ, Cutando A and Reiter RJ: Melatonin in diseases of the oral cavity. Oral Dis 16: 242-247, 2010.

55. Chaiyarit P, Ma N, Hiraku Y, Pinlaor S, Yongvanit P, Jintakanon D, Murata M, Oikawa S and Kawanishi S: Nitrative and oxidative DNA damage in oral lichen planus in relation to human oral carcinogenesis. Cancer Sci 96: 553-559, 2005.

56. Cutando A, Aneiros-Fernández J, López-Valverde A Arias-Santiago S, Aneiros-Cachaza J and Reiter RJ: A new perspective in oral health: potential importance and actions of melatonin receptors MT1, MT2, MT3, and RZR/ROR in the oral cavity. Arch Oral Biol 56: 944-950, 2011.

57. Cutando A, Aneiros-Fernández J, Aneiros-Cachaza J and Arias-Santiago S: Melatonin and cancer: current knowledge and its application to oral cavity tumours. J Oral Pathol Med 40: 593-597, 2011. 